To appear in: The Handbook of the Neuroscience of Multilingualism (John W. Schwieter Eds. - Wiley-Blackwell)

\title{
Multilingualism and metacognitive processing
}

\author{
Peter Bright ${ }^{1}$, Julia Ouzia ${ }^{2}$, \& Roberto Filippi ${ }^{3}$ \\ ${ }^{1}$ Anglia Ruskin University, Cambridge \\ ${ }^{2}$ Goldsmiths, University of London \\ ${ }^{3}$ University College London - Institute of Education
}

\section{Acknowledgements}

This work was supported by the Leverhulme Trust UK [RPG-2015-024] and the British Academy [SG162171]. 


\section{Multilingualism and metacognitive processing}

\subsection{Introduction}

Modern understanding of the term 'metacognition' encompasses two levels of processing: a lower level awareness or knowledge of one's own thoughts and a higher level regulation or control of our thinking (Fernandez-Duque, Baird, \& Posner, 2000; Fleming, Ryu, Golfinos, \& Blackmon, 2014; Paris \& Winograd, 1990; McCormick, 2003). Cognition and metacognition are therefore mutually dependent functions that serve our ability to interact with our environment in an adaptive, goal-directed manner. Without effective metacognition, we would not be able to adjust our cognitive strategies towards goalachievement because we would lack insight into ongoing levels of performance. This notion of metacognition both as a comparatively passive (knowledge/awareness) function and an active (regulatory/control) function is problematic because it renders the term rather inseparable from the well-established concept of executive function: both are concerned with top down monitoring and control of cognition and behaviour. In order to progress theory on metacognitive processing, therefore, it is crucial to determine the conceptual relationship between the two, not least because advances in theoretical knowledge are unlikely to be realised by replacing one (arguably) poorly defined concept with another.

The claim that multi-language acquisition drives advantages in executive function is currently an issue of vigorous debate in the literature. To the extent that the claim is true, we might predict a multilingual benefit in metacognitive ability commensurate with the level of conceptual overlap. Until recently, however, the literature has been largely silent on this issue and the only study to date that has directly and empirically compared metacognitive performance in multilingual and monolingual participants indicates a multilingual disadvantage (Folke, Ouzia, Bright, De Martino, \& Filippi, 2016). 
In this chapter, we critically review evidence for overlap and divergence in the neural and psychological basis of metacognition and executive function, and consider the implications for current debate on the proposed cognitive advantages associated with the acquisition and regular use of two or more languages.

\subsection{Metacognition and executive function - conceptual overlap}

Executive function refers to 'higher-order' cognitive processes that together allow us to function effectively in complex environments (Baddeley \& Hitch, 1974; Norman \& Shallice, 1986; Baddeley, 2017). Terms such as attentional control, inhibition, planning, sustained/selective attention, task switching, and error monitoring can all be grouped under the conceptual umbrella of executive function. The widely accepted fundamental assumptions of this executive or 'attentional' system are i. limited capacity (our resources are limited in the sense that we can only process a portion of the information available to us at one time; Broadbent, 1958; Desimone \& Duncan, 1995), and ii. selectivity (optimally, selection of information into the system is biased towards that information currently relevant to ongoing goals; Norman \& Shallice, 1986). Of course, an environment can be complex not only in terms of physical characteristics and visual 'noise' with different objects competing for our attention. It can also exert complexity across other input modalities, in which, for example, auditory information from multiple sources can compete for our attention. One crucial issue is whether the limited capacity and goal-directed selectivity of our executive system can somehow be enhanced or otherwise benefit from the continuous, intense competition associated with multilingual environments. If we are to fully understand the nature of this relationship, we also need to consider which cognitive control mechanisms are influenced by the enhanced competition associated with multilingual contexts. Here, we 
focus on the relationship between executive function and metacognitive abilities and consider whether and how multilingualism might impact upon them.

The concept of metacognition originated in the early 1970s with the work of John Flavell and others (e.g., Flavell, 1971; Butterfield, Wambold, \& Belmont, 1973; Brown, 1975). The early focus was on metamemory, which Flavell described as the knowledge and monitoring of memory storage and retrieval. When used effectively, metamemory skills ensure optimised memory performance via the regulatory process of calibrating subjective estimates of performance against actual performance, with the latter modified accordingly (Roebers, 2017). Thus, the notion of active control as well as more passive monitoring was incorporated, with the broader concept of metacognition formally introduced by Flavell (1979) to encompass the monitoring and control of all declarative cognitive activity. If we accept that executive function and metacognitive regulation serve the coordination of domain-general cognitive activity in the service of goal-relevant behaviour, it is reasonable to challenge the assumption that they are dissociable functions.

On a theoretical level, it has been argued that metacognition operates on two interacting levels - the object level (bottom up cognitive monitoring) and the meta-level (top down control; Nelson \& Narens, 1990, 1994). Fernandez-Duque, Baird, \& Posner (2000) raise similarities in this conceptualisation with Norman and Shallice's (1986) model of executive function, in which a higher level supervisory attentional mechanism monitors and manipulates automatic processes (action schemas), thereby exhibiting control over them (Figure 1). 


\section{Metacogniton}

(Nelson \& Narens, 1994)
Executive System

(Norman \& Shallice, 1986)

\section{Meta-level

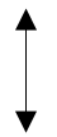 \\ Object level}

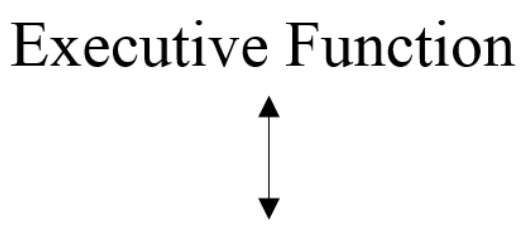

Schemas

Figure 1. Illustration of the conceptual overlap of metacognition and the executive system (adapted from Fernandez-Duque et al., 2000).

Intuitively, therefore, if metacognition is closely associated with mechanisms of cognitive control (i.e., selective attention, response inhibition, task switching, etc.), we would expect to observe metacognitive advantages alongside benefits in executive function. Empirical evidence has supported this argument of positive correlation between measures of metacognitive and executive function, demonstrating that inhibitory control correlates with the ability to accurately apply rules in decision making tasks (Del Missier, Mäntylä, \& Bruine de Bruin, 2010; Souchay \& Isingrini, 2004). It has also been claimed that attentional shifting between task constraints supports the ability to provide consistent/accurate performance judgements (Del Missier, Mäntylä, \& Bruine de Bruin, 2010) as well as prospective confidence judgements (feeling-of-knowing) on a metamemory task involving memorising cue-target word combinations (Boduroglu, Tekcan \& Kapucu, 2014).

There are clearly important similarities between modern conceptualisation of metacognition and executive function, both referring to systems that serve our ability to think 
and behave in a purposive, goal-directed manner when confronted with complex situations in which multiple responses are available to us at any one time (i.e., in our typical daily lives). Orchestration of our activities relies not only on our ability to overturn strong goal-irrelevant response tendencies (e.g., overturning the urge to go back to sleep after the early morning alarm has sounded) or to sustain our attention on a difficult task through to completion, but also to understand the relationship between our actions and objective performance towards our goals. Without accurate monitoring of our ongoing learning and performance (i.e., in situations in which our subjective judgement of our cognitive performance is poorly calibrated with actual performance) we are unable to optimally regulate our knowledge or strategies in the service of goal attainment.

\subsection{Metacognition and executive function - neuroanatomical considerations}

Aside from evaluating the theoretical functional overlap between metacognitive regulation and executive function, Fernandez-Duque and colleagues (2000) provided initial pointers with regards to the discussion of the neuroanatomical overlap in the two systems. The fundamental tenet of their argument is that mechanisms associated with high level cognitive control, such as conflict resolution, monitoring, and emotional regulation, are a necessary element of successful metacognition. To a far greater extent, executive function has attracted a concerted effort by neuropsychologists and cognitive neuroscientists to identify and tease apart the underlying neural mechanisms that together serve our ability to produce complex goal-directed behaviour. This literature identifies widely distributed networks serving high level cognitive control, but within which regions of the frontal lobes are of

fundamental importance. Both metacognitive and executive control serve the optimisation of performance and decision-making in novel and uncertain situations (e.g., Fedorenko, Duncan \& Kanwisher, 2013; Woolgar, Parr, Cusack, et al., 2010), and we might therefore predict 
considerable overlap in their neural signatures. In interpreting this literature, however, caution must be applied due to the challenge of excluding activity associated with lowerorder processing (i.e., task-specific perceptual information, memory content, etc.) rather than the higher-order or 'meta' processes that are the target of investigation (Roebers, 2017).

A broad network of frontal areas, including the anterior cingulate and supplementary motor area, the orbitofrontal cortex, the dorsolateral prefrontal cortex, as well as non-frontal cortical and subcortical structures are implicated in high-level executive control (FernandezDuque, Baird \& Posner, 2000). The role of frontoparietal connectivity in the service of executive attentional control and psychometric intelligence is also an important theme in the literature.

In comparison to executive function, the neuroanatomical basis of metacognition is poorly specified, and while earlier studies provide broad consistency with neuropsychological studies of executive function (i.e., a sensitivity to frontal lesions), they lack anatomical specificity. Janowsky, Shimamura and Squire (1989) reported metamemory impairments in patients with frontal lesions (but intact metamemory in temporal lobe amnesic patients). They also identified metamemory impairment in patients with Korsakoff syndrome (in which frontal involvement is typically implicated in addition to diencephalic disturbance), consistent with an important role of the frontal lobes in metamemory judgements (see also Modirrousta \& Fellows, 2008; Parkin, Bell \& Leng, 1988). A review of neuropsychological studies provides confirmatory evidence that the neural correlates of metamemory are distinct from fundamental primary memory encoding and retrieval processes, and are served, in large part, by the frontal lobes (Pannu \& Kazniak, 2005). Consistent with this proposed dissociation in the networks serving meta- and primary memory functions a recent transcranial direct current stimulation (tDCS) study, in which the dorsolateral prefrontal cortex was positively stimulated, reduced confidence ratings in a visual short-term memory 
task (in comparison to a sham condition), but left trial accuracy intact (Bona \& Silvanto, 2014).

Recent developments in structural imaging technology have provided the opportunity for more accurate lesion delineation and quantification, and a more precise characterisation of frontal involvement in metamemory is emerging. Our ability to monitor and estimate our performance on memory tasks can be separated into prospective and retrospective judgements. The former is characterised as 'feeling of knowing' how well we will perform on some future task, while the latter refers to judgement of how well we have performed on a completed task or trial. In a structural MRI study of abstinent alcoholics and neurologically healthy controls, Le Berre et al. (2016) found evidence for a structure-function double dissociation in which volumetric measurements of the insular cortex selectively covaried with feeling-of-knowing judgements and frontolimbic volumes selectively covaried with retrospective confidence judgements (consistent with the literature on metamemory impairment in Korsakoff syndrome, as outlined above). Other studies indicate that prospective judgements may be supported by medial prefrontal cortex structures, whilst retrospective judgements depend on lateral PFC (Fleming \& Dolan, 2012). For example, whilst lesions in the ventro-medial prefrontal cortex are associated with decreased feeling of knowing accuracy, the accuracy of confidence judgements is preserved (Schnyer et al., 2004). Conversely, retrospective confidence judgements may be impaired following rostrolateral prefrontal lesions while actual task execution performance is unaffected (Fleming \& Dolan, 2012). The anterior cingulate cortex has also been identified as an important part of a distributed metacognition network, with functional neuroimaging and electrophysiological (EEG) evidence for a key role in prediction and monitoring of task performance, and detection of novelty or conflict (e.g., Metcalfe, Butterfield, Habeck, \& Stern, 2012; Do Lam et al., 2012; for reviews see Roebers, 2017; Schwartz \& Metcalfe, 2017). 
Together, these findings provide a potential neurocognitive link between metacognition, executive function and the cognitive advantages reported in bilinguals. Nevertheless, research evaluating the relationship between attentional set shifting (on the trail making test; Reitan, 1958), considered an important executive control mechanism, and metacognitive efficiency did not detect a relationship between the two functions (Palmer, David, \& Fleming, 2014). Given the argument that the multilingual advantage may derive in large part from the demands associated with regular switching between two or more languages (e.g., Bialystok, Craik, \& Luk, 2012; Wiseheart, Viswanathan, \& Bialystok, 2016), such findings raise the possibility that advantages may well be observed in aspects of executive function, but leave metacognitive abilities unaffected, or even disadvantaged (as has been reported by Folke, Ouzia, Bright, De Martino, \& Filippi, 2016, discussed below). Other authors have, however, reported links between metacognitive control over task performance and other components of executive function, such as response inhibition (Pansky, Goldsmith, Koriat, \& Pearlman-Avnion, 2009; Souchay \& Isingrini, 2004). Problems in definition and separability among concepts/labels such as task/set shifting, response inhibition, sustained attention, updating etc., continue to obfuscate the ability to clearly and selectively identify specific mechanisms of cognitive control, and the relationship between each of these mechanisms and metacognitive functions therefore remains uncertain. There is likely to be unity and diversity within and between executive and metacognitive operations and the current lack of clarity represents a significant obstacle to progress.

\subsection{Metacognition and multilingualism}

Despite the large body of literature focused on the impact of multi-language learning on executive function, and the suggestions concerning a conceptual and neural overlap between cognitive control and metacognition, very few studies have explicitly addressed the 
possibility that multilingualism may impact on metacognitive processing. Research on bilingualism indicates that bilingual university students have better insight into their reading comprehension abilities compared to their monolingual peers (Ransdell, Barbier, \& Niit, 2006), that children who learned a second language in a formal context display an increased awareness and use of communicational strategies (Le Pichon, de Swart, Vorstman, \& van den Bergh, 2010; Le Pichon, Vortsman, de Swart, Cegniskas, \& van den Bergh, 2009), and that proficient multilingualism is associated with the flexible use of grammatical (Kemp, 2009) as well as reading strategies (García, Jiménez \& Pearson, 1998).

However, to date, there is only one report in the published literature evaluating general metacognitive abilities in multilingual individuals that are not related to their linguistic performance. Folke and colleagues (2016) administered a two-alternative-forcedchoice task across two experiments. First, participants had to determine which one of two circles contained the most number of dots (first order task). Following on from this, participants had to state their confidence in their choice (second order task; see Figure 2 for an illustration). In one experiment, in which the first order task was not time-constrained, bilinguals were found to respond faster than monolinguals but were significantly less metacognitively efficient, with efficiency mathematically determined by the difference between expected and observed performance (see section 5.0 for further information on the calculation of metacognitive efficiency). The findings suggested that in comparison to monolinguals, bilinguals tended to feel less confident in trials they completed correctly and more confident in trials where their performance was incorrect. In a second experiment in which the response time window for the first order task was experimentally constrained, the bilingual metacognitive disadvantage was replicated despite statistically equal response times in the two groups. Therefore, the metacognitive disadvantage in the bilingual group appeared 
robust, and unrelated to group differences in visual discrimination speed and/or reaction times.

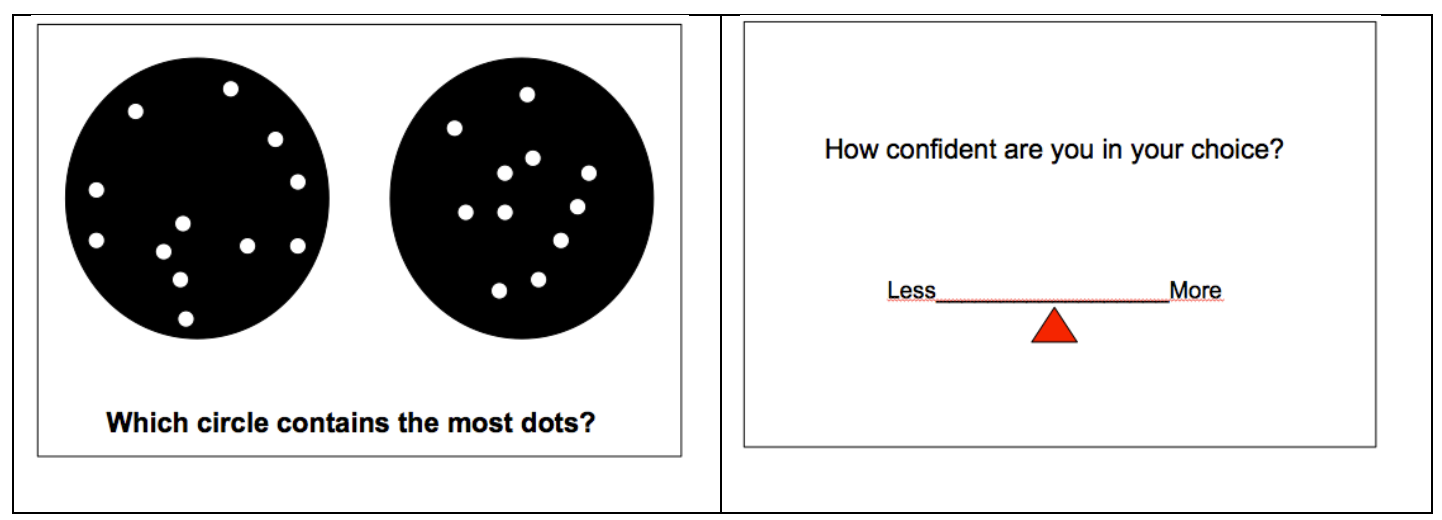

Figure 2. Two-alternative-forced-choice task employed by Folke and colleagues (2016)

This finding of a metacognitive disadvantage is seemingly at odds with the literature. For example, in their systematic review and meta-analysis of 63 studies of the cognitive correlates of bilingualism, Adesope, Lavin, Thompson \& Ungerleider (2010) identified a reliable association between bilingualism and metalinguistic awareness. To resolve this apparent discrepancy it is instructive to consider the relationship between metacognitive and metalinguistic processing. Although, intuitively, 'meta' abilities may be considered a family of interrelated functions, metacognitive and metalinguistic awareness may be served - at least in part - by distinct cognitive mechanisms (for discussion of this theme, see Van Kleeck, 1982). This argument mirrors the uncertain relationship between metacognition and executive function. The relationship between executive function and psychometric intelligence is also fiercely debated in the literature (e.g., Duncan et al., 2008; Carroll \& Bright, 2016; Deary, 2001; Kane \& Engle, 2002) and the relationship of the 'bilingual advantage' to psychometric intelligence is similarly complicated (e.g., Peal \& Lambert, 1962; Bialystok \& Martin, 2004; for a review see Barac, Bialystok, Castro \& Sanchez, 2014). At a conceptual level, these 
labels given to mechanisms of high level cognition are very difficult to tease apart, to the extent that we cannot confidently argue either that they refer to dissociable cognitive systems or otherwise identify the extent to which component processes are shared across these 'systems'.

Despite these issues, evidence that there may be metacognitive disadvantages associated with multilingualism and that these coexist with advantages in executive function and metalinguistic ability indicates some level of dissociability among the proposed systems and that we might also observe disparity in the underlying neural signatures. In a recent review, Roebers (2017) sought to bring together the literature on metacognition and executive function and build a unifying framework to promote theoretical understanding of cognitive self-regulation. The extent to which the process of becoming multilingual may facilitate or interfere with such domain general self-regulatory skills is an important question yet the literature to-date focuses on executive function and neglects metacognition, possibly because the two research fields are rooted in quite different research traditions. As a first step towards developing our understanding of interactions between multilingualism and metacognition, we provide a brief critical review of empirical approaches typically employed for exploring metacognitive abilities.

\subsection{Description and critique of methods used for measuring metacognition}

Metacognitive awareness is often quantified via confidence judgements in relation to a specific measure of cognitive task performance, such as accuracy or error rate (e.g., De Martino, Fleming, Garrett, \& Dolan, 2013; Schwartz \& Díaz, 2014; Yeung \& Summerfield, 2014). This degree of fit between an individual's estimate of performance and actual performance is commonly referred to as calibration (Bol \& Hacker, 2012; Keren, 1991; Nelson, 1996), and allows identification of overconfidence and underconfidence in actual 
performance. It is considered a fundamental requirement for the successful regulation of ongoing purposive behavior, because it is only through accurate calibration of actual against self-estimated performance that optimal efficiency in performance can be achieved. Consistent with this claim, for example, a large body of evidence indicates that actual achievement in educational settings is highly sensitive to calibration accuracy (for a review see Bol \& Hacker, 2012).

Historically, then, the relationship between confidence and actual performance has been evaluated via a calibration curve (Hart, 1967), in which the objectivity or precision of an individual's monitoring of task performance is plotted against actual performance (Kornell, Son, \& Terrace, 2007; Nelson, 1984; Roebers, 2017). However, the limitations of this approach have been challenged on the basis of failure to distinguish between an individual's metacognitive sensitivity (or accuracy) and their bias towards over- or under-confidence; the former tends to be task specific but the latter is typically more of a stable or enduring tendency (Fleming \& Lau, 2014; Fleming, Massoni, Gajdos \& Vergnaud, 2016), although it has been shown to interact in some cases with straightforwardness of the task (Fleming et al., 2016; Gigerenzer, Hoffrage, \& Kleinbolting, 1991). Cortical stimulation studies have provided confirmatory evidence that confidence judgements and objective accuracy can be interrupted independently of each other and are therefore served by (at least partially) independent networks (Fleming, Maniscalco, Ko, Amendi, Ro, \& Lau, 2015; Rahnev, Nee, Riddle, Larson, \& D’Esposito, 2016).

Signal detection theory can be applied to isolate metacognitive sensitivity from confidence bias because it provides separate measures for each of these components. However, studies have shown that the sensitivity index (or d') remains confounded by metacognitive bias, due to violation of distribution assumptions (e.g., Evans \& Azzopardi, 2007; Fleming \& Lau, 2014). In response to this problem, Maniscalco \& Lau $(2012,2014)$ 
developed meta-d' which offers a more robust measure of metacognitive accuracy (e.g., Baird, Smallwood, Gorgolewski, \& Margulies, 2013; Barrett, Dienes, \& Seth, 2013) with metacognitive efficiency (MRatio) computed as the fraction between meta-d' and d' (Fleming \& Lau, 2014) such that an MRatio of 1 would denote confidence ratings that perfectly reflect first order accuracy. The advantages of this this approach have been recognised in the literature and meta-d' has already been exploited in a range of studies (e.g., Charles, van Opstal, Marti, \& Dehaene, 2013; Folke et al., 2016; Lee, Blumenfeld, \& D’Esposito, 2013; McCurdy et al., 2013).

The literature has not, to date, provided consistent evidence for a stable metacognitive ability, possibly due to the considerable empirical difficulty of quantifying performanceconfidence relationships, which is inherently more subjective and challenging than quantification of task performance itself (Fleming \& Dolan, 2012). Authors typically, therefore, recommend very large numbers of trials to elicit reliable and consistent estimation of metacognitive performance (see also Kelemen, Frost, \& Weaver, 2000). Nevertheless, individual variability in metacognitive sensitivity across trials and between tasks may be of interest in its own right, and we do not currently know whether stability vs lability covaries with other variables of theoretical interest, such as psychometric intelligence or mechanisms associated with multilingualism.

\subsection{Executive function, metacognition and multilingualism}

In Abutalebi and Green's (2007) model of language processing in bilinguals, both languages are served by a common distributed network, but multi-language contexts place additional demands on left prefrontal cortex, anterior cingulate cortex, parietal cortex and left caudate nucleus, all regions associated with inhibitory control (e.g., Bunge, Dudukovic, 
Thomason, Vaidya \& Gabrieli, 2001; Wiecki \& Frank, 2013; Durston, Thomas, Yang, Uluğ, Zimmerman \& Casey, 2002) and metacognition (e.g., Chua, Schacter, Rand-Giovannetti, \& Sperling, 2006; Molenberghs, Trautwein, Bockler, Singer, \& Kanske, 2016). In the Molenberghs et al. functional MRI study, increased confidence in performance on a social and cognitive reading test was associated with increased caudate activity but lower metacognitive accuracy. Evidence that the left and/or right caudate nucleus (along with other subcortical structures including the thalamus and putamen) is significantly larger in bilinguals than monolinguals (Burgaleta, Sanjuán, Ventura, Sebastian-Gallés, \& Ávila, 2016; Zou, Ding, Abutalebi, Shu, \& Peng, 2012) is consistent with a striatal gating system that controls the neocortical recruitment serving language processing and control (e.g., Stocco, Yamasaki, Natalenko \& Prat, 2014). It also raises the possibility, though speculative, that emotional regulation via the striatum may differentially affect the relationship between metacognitive judgement of task performance and actual performance in multilinguals and monolinguals. Whatever the nature of the cortical and subcortical developmental effects of multi-language acquisition, converging evidence is emerging that multilingualism impacts on a broad, distributed network of brain regions, including both primary language and domain general/nonverbal processing sites involved in emotional regulation and higher level cognitive control. Within this system, structures associated with executive attention and the resolution of response competition (particularly the fronto-parietal network and anterior cingulate cortex) are most likely to be the primary 'hub' driving structural change in the rest of the system in the service of operating more effectively in complex multi-lingual environments. 


\subsection{Concluding points}

Over the past decade, the 'bilingual advantage' has broadened from a relatively narrow focus on inhibitory control to incorporate Theory of Mind (Rubio-Fernández \& Glucksberg, 2012), rule-based learning (Stocco \& Prat, 2014), reactive and proactive control (Morales, Gómez-Ariza \& Bajo, 2013), visuo-spatial memory (Kerrigan, Thomas, Bright \& Filippi, 2017) and controlling verbal interference in speech comprehension (Filippi, Leech, Thomas, Green, \& Dick, 2012; Filippi et al., 2015). The claim that the process of becoming bilingual may impact on metacognitive abilities adds to this broadening focus, but may also benefit the resolution of ongoing debate about the selectivity of cognitive changes associated with multilingualism. One obstacle to progress in this regard is the tendency in the literature to treat 'executive function' as a unitary fronto-parietal system recruited in response to all manner of cognitive demand, yet performance across so called 'executive function' tasks is highly variable and intercorrelations are sometimes low (Miyake et al., 2000). In their largescale recent review, Friedman and Miyake (2017) break executive function down into three intermediate components: inhibition, updating in working memory and task-set shifting. This characterisation is not meant to infer three unitary and dissociable constructs serving broader executive control, but it does provide a framework for finer-grained analysis of the 'family resemblance' of impairment typically observed in patients with dysexecutive syndrome following frontal lobe damage, and the types of error produced by neurologically healthy participants on complex tasks. In our view, frameworks such as that proposed by Miyake and Friedman (2017) provide a sensible basis for identifying fractionation of processes associated with executive control. As reviewed here, in the only laboratory study of metacognitive effects associated with multilingualism published to date, a metacognitive disadvantage was observed (Folke et al., 2016), and this raises a theoretically compelling argument for future research not only to replicate and further characterise this effect, but potentially to exploit it 
in order to further characterise unity and diversity in the relationships among components of executive function and metacognition. 


\section{References}

Abutalebi, J., \& Green, D. (2007). Bilingual language production: The neurocognition of language representation and control. Journal of neurolinguistics, 20(3), 242-275.

Adesope, O. O., Lavin, T., Thompson, T., \& Ungerleider, C. (2010). A systematic review and meta-analysis of the cognitive correlates of bilingualism. Review of Educational Research, 80(2), 207-245.

Baddeley, A. D. (2017). Modularity, working memory and language acquisition. Second Language Research, 33, 299 - 311.

Baddeley, A. D., \& Hitch, G. (1974). Working memory. Psychology of learning and motivation, 8, 47-89.

Baird, B., Smallwood, J., Gorgolewski, K. J., \& Margulies, D. S. (2013). Medial and lateral networks in anterior prefrontal cortex support metacognitive ability for memory and perception. Journal of Neuroscience, 33(42), 16657-16665.

Barac, R., Bialystok, E., Castro, D. C., \& Sanchez, M. (2014). The cognitive development of young dual language learners: A critical review. Early Childhood Research Quarterly, 29(4), 699-714.

Barrett, A. B., Dienes, Z., \& Seth, A. K. (2013). Measures of metacognition on signaldetection theoretic models. Psychological methods, 18(4), 535.

Bialystok, E., Craik, F. I., \& Luk, G. (2012). Bilingualism: consequences for mind and brain. Trends in cognitive sciences, 16(4), 240-250.

Bialystok, E., \& Martin, M. M. (2004). Attention and inhibition in bilingual children: Evidence from the dimensional change card sort task. Developmental Science, 7(3), 325-339.

Boduroglu, A., Tekcan, A. İ., \& Kapucu, A. (2014). The relationship between executive functions, episodic feeling-of-knowing and confidence judgements. Journal of Cognitive Psychology, 26(3), 333-345. 
Bol, L., \& Hacker, D. J. (2012). Calibration research: where do we go from here? Frontiers in psychology, 3, 1-6.

Bona, S., \& Silvanto, J. (2014). Accuracy and confidence of visual short-term memory do not go hand-in-hand: behavioral and neural dissociations. PLoS One, 9(3), e90808.

Broadbent, D (1958). Perception and Communication. London: Pergamon Press.

Brown, A. L. (1975). The development of memory: Knowing about knowing, and knowing how to know. In H. W. Reese (Ed.), Advances in child development and behavior (Vol. 10, pp. 103-152). New York: Academic Press

Bunge, S. A., Dudukovic, N. M., Thomason, M. E., Vaidya, C. J., \& Gabrieli, J. D. (2002). Immature frontal lobe contributions to cognitive control in children: evidence from fMRI. Neuron, 33(2), 301-311.

Burgaleta, M., Sanjuán, A., Ventura-Campos, N., Sebastian-Galles, N., \& Ávila, C. (2016). Bilingualism at the core of the brain. Structural differences between bilinguals and monolinguals revealed by subcortical shape analysis. NeuroImage, 125, 437-445.

Butterfield, E. C., Wambold, C., \& Belmont, J. M. (1973). On the theory and practice of improving short-term memory. American Journal of Mental Deficiency, 77, 654-669.

Carroll, E. L., \& Bright, P. (2016). Involvement of Spearman's g in conceptualisation versus execution of complex tasks. Acta psychologica, 170, 112-126.

Charles L., Van Opstal F., Marti S., Dehaene S. (2013). Distinct brain mechanisms for conscious versus subliminal error detection. Neuroimage, 73, 80-94.

Chua, E. F., Schacter, D. L., Rand-Giovannetti, E., \& Sperling, R. A. (2006). Understanding metamemory: neural correlates of the cognitive process and subjective level of confidence in recognition memory. Neuroimage, 29(4), 1150-1160. 
Deary, I. J. (2001). Human intelligence differences: towards a combined experimental-differential approach. Trends in Cognitive Sciences, 5(4), 164-170.

De Martino, B., Fleming, S. M., Garrett, N., \& Dolan, R. J. (2013). Confidence in value-based choice. Nature neuroscience, 16(1), 105-110.

Del Missier, F., Mäntylä, T., \& Bruine de Bruin, W. (2010). Executive functions in decision making: An individual differences approach. Thinking \& Reasoning, 16(2), 69-97.

Desimone, R., \& Duncan, J. (1995). Neural mechanisms of selective visual attention. Annual review of neuroscience, 18(1), 193-222.

Do Lam, A. T., Axmacher, N., Fell, J., Staresina, B. P., Gauggel, S., Wagner, T., ... \& Weis, S. (2012). Monitoring the mind: The neurocognitive correlates of metamemory. PloS one, $7(1)$, e30009.

Duncan, J., Parr, A., Woolgar, A., Thompson, R., Bright, P., Cox, S., ... \& NimmoSmith, I. (2008). Goal neglect and Spearman's g: competing parts of a complex task. Journal of Experimental Psychology: General, 137(1), 131.

Durston, S., Thomas, K. M., Yang, Y., Uluğ, A. M., Zimmerman, R. D., \& Casey, B. J. (2002). A neural basis for the development of inhibitory control. Developmental Science, $5(4)$.

Evans, S., \& Azzopardi, P. (2007). Evaluation of a'bias-free'measure of awareness. Spatial vision, 20(1), 61-77.

Fedorenko, E., Duncan, J., \& Kanwisher, N. (2013). Broad domain generality in focal regions of frontal and parietal cortex. Proceedings of the National Academy of Sciences, 110(41), 16616-16621.

Fernandez-Duque, D., Baird, J. A., \& Posner, M. I. (2000). Executive attention and metacognitive regulation. Consciousness and cognition, 9(2), 288-307. 
Filippi, R., Leech, R., Thomas, M. S., Green, D. W., \& Dick, F. (2012). A bilingual advantage in controlling language interference during sentence comprehension. Bilingualism: Language and Cognition, 15(4), 858-872.

Filippi, R., Morris, J., Richardson, F. M., Bright, P., Thomas, M. S., Karmiloff-Smith, A., \& Marian, V. (2015). Bilingual children show an advantage in controlling verbal interference during spoken language comprehension. Bilingualism: Language and Cognition, $18(3), 490-501$

Flavell, J. H. (1971). "First discussant's comments: What is memory development the development of?". Human Development, 14, 272.

Flavell, J. H. (1979). Metacognition and cognitive monitoring: A new area of cognitive-developmental inquiry. American psychologist, 34(10), 906.

Fleming, S. M., \& Dolan, R. J. (2012). The neural basis of metacognitive ability. Philosophical Transactions of the Royal Society of London, B Biological Sciences, 367, $1338-1349$

Fleming, S. M., \& Lau, H. C. (2014). How to measure metacognition. Frontiers in Human Neuroscience, 8, 443.

Fleming, S. M., Maniscalco, B., Ko, Y., Amendi, N., Ro, T., \& Lau, H. (2015). Action-specific disruption of perceptual confidence. Psychological Science, 26(1), 89-98.

Fleming, S. M., Massoni, S., Gajdos, T., \& Vergnaud, J. C. (2016). Metacognition about the past and future: quantifying common and distinct influences on prospective and retrospective judgments of self-performance. Neuroscience of Consciousness, 2016(1), niw018.

Fleming, S. M., Ryu, J., Golfinos, J. G., \& Blackmon, K. E. (2014). Domain-specific impairment in metacognitive accuracy following anterior prefrontal lesions. Brain, 137(10), 2811-2822. 
Folke, T., Ouzia, J., Bright, P., De Martino, B., \& Filippi, R. (2016). A bilingual disadvantage in metacognitive processing. Cognition, 150, 119-132.

Friedman, N. P., \& Miyake, A. (2017). Unity and diversity of executive functions: Individual differences as a window on cognitive structure. Cortex, 86, 186-204.

García, G. E., Jiménez, R. T., \& Pearson, P. D. (1998). Metacognition, childhood bilingualism, and reading. In D. J. Hacker, J. Dunlosky, \& A. C. Graesser (Eds.), Metacognition in educational theory and practice (pp. 193-219). Mahwah, NJ: Erlbaum.

Gigerenzer, G., Hoffrage, U., \& Kleinbölting, H. (1991). Probabilistic mental models: A Brunswikian theory of confidence. Psychological review, 98(4), 506.

Hart, J. T. (1967). Memory and the memory-monitoring process. Journal of Verbal Learning and Verbal Behavior, 6, 685-691.

Janowsky, J. S., Shimamura, A. P., \& Squire, L. R. (1989). Memory and metamemory: Comparisons between patients with frontal lobe lesions and amnesic patients. Psychobiology, 17(1), 3-11.

Kane, M. J., \& Engle, R. W. (2002). The role of prefrontal cortex in working-memory capacity, executive attention, and general fluid intelligence: An individual-differences perspective. Psychonomic bulletin \& review, 9(4), 637-671.

Kelemen, W. L., Frost, P. J., \& Weaver, C. A. (2000). Individual differences in metacognition: Evidence against a general metacognitive ability. Memory \& Cognition, 28(1), 92-107.

Kemp, C. (2009). Defining multilingualism. The Exploration of Multilingualism: Development of research on L3, multilingualism and multiple language acquisition, 6, 11 .

Keren, G. (1991). Calibration and probability judgements: Conceptual and methodological issues. Acta Psychologica, 77(3), 217-273. 
Kerrigan, L., Thomas, M. S., Bright, P., \& Filippi, R. (2017). Evidence of an advantage in visuo-spatial memory for bilingual compared to monolingual speakers. Bilingualism: Language and Cognition, 20(3), 602-612.

Kornell, N., Son, L. K., \& Terrace, H. S. (2007). Transfer of metacognitive skills and hint seeking in monkeys. Psychological Science, 18(1), 64-71.

Lee T. G., Blumenfeld R. S., D'Esposito M. (2013). Disruption of dorsolateral but not ventrolateral prefrontal cortex improves unconscious perceptual memories. Journal of Neuroscience, 33, 13233-13237.

Le Berre, A. P., Müller-Oehring, E. M., Kwon, D., Serventi, M. R., Pfefferbaum, A., \& Sullivan, E. V. (2016). Differential compromise of prospective and retrospective metamemory monitoring and their dissociable structural brain correlates. Cortex, 81, 192202.

Le Pichon, E., de Swart, H., Vorstman, J., \& van den Bergh, H. (2010). Influence of the context of learning a language on the strategic competence of children. International Journal of Bilingualism, 14(4), 447-465.

Le Pichon Vorstman, E., De Swart, H., Ceginskas, V., \& Van Den Bergh, H. (2009). Language learning experience in school context and metacognitive awareness of multilingual children. International Journal of Multilingualism, 6(3), 258-280.

Maniscalco, B., \& Lau, H. (2012). A signal detection theoretic approach for estimating metacognitive sensitivity from confidence ratings. Consciousness and cognition, $21(1), 422-430$.

Maniscalco, B., \& Lau, H. (2014). Signal detection theory analysis of type 1 and type 2 data: meta- $\mathrm{d}^{\prime}$, response-specific meta- $\mathrm{d}^{\prime}$, and the unequal variance SDT model. In The cognitive neuroscience of metacognition (pp. 25-66). Springer Berlin Heidelberg. 
McCormick, C. B. (2003). Metacognition and learning. In W. M. Reynolds \& G. E. Miller (Eds.), Handbook of Psychology, Volume 7 (pp. 79-102). Hoboken, NJ: Wiley.

McCurdy L. Y., Maniscalco B., Metcalfe J., Liu K. Y., de Lange F. P., Lau H. (2013). Anatomical coupling between distinct metacognitive systems for memory and visual perception. Journal of Neuroscience, 33, 1897-1906.

Metcalfe, J., Butterfield, B., Habeck, C., \& Stern, Y. (2012). Neural correlates of people's hypercorrection of their false beliefs. Journal of cognitive neuroscience, 24(7), 15711583

Miyake, A., Friedman, N. P., Emerson, M. J., Witzki, A. H., Howerter, A., \& Wager, T. D. (2000). The unity and diversity of executive functions and their contributions to complex "frontal lobe" tasks: A latent variable analysis. Cognitive psychology, 41(1), 49-100.

Modirrousta, M., \& Fellows, L. K. (2008). Medial prefrontal cortex plays a critical and selective role in 'feeling of knowing'meta-memory judgments. Neuropsychologia, 46(12), 2958-2965.

Molenberghs, P., Trautwein, F. M., Böckler, A., Singer, T., \& Kanske, P. (2016). Neural correlates of metacognitive ability and of feeling confident: a large-scale fMRI study. Social cognitive and affective neuroscience, 11(12), 1942-1951.

Morales, J., Gómez-Ariza, C. J., \& Bajo, M. T. (2013). Dual mechanisms of cognitive control in bilinguals and monolinguals. Journal of Cognitive Psychology, 25(5), 531-546.

Nelson, T. O. (1984). A comparison of current measures of the accuracy of feeling-ofknowing predictions. Psychological Bulletin, 95, 109-133.

Nelson, T. O. (1996). Consciousness and metacognition. American psychologist, 51(2), 102 .

Nelson, T. O., \& Narens, L. (1990). Metamemory: A theoretical framework and new findings. Psychology of learning and motivation, 26, 125-173. 
Nelson, T. O., \& Narens, L. (1994). Why investigate metacognition? In J. Metcalfe \& A. Shimamura (Eds.), Metacognition: Knowing about knowing (pp. 1-25). Cambridge, MA: Bradford Books.

Norman, D. A., \& Shallice, T. (1986). Attention to action. In Consciousness and selfregulation (pp. 1-18). Springer US.

Palmer, E. C., David, A. S., \& Fleming, S. M. (2014). Effects of age on metacognitive efficiency. Consciousness and cognition, 28, 151-160.

Pannu, J. K., \& Kaszniak, A. W. (2005). Metamemory experiments in neurological populations: A review. Neuropsychology review, 15(3), 105-130.

Pansky, A., Goldsmith, M., Koriat, A., \& Pearlman-Avnion, S. (2009). Memory accuracy in old age: Cognitive, metacognitive, and neurocognitive determinants. European Journal of Cognitive Psychology, 21(2-3), 303-329.

Parkin, A. J., Bell, W. P., \& Leng, N. R. (1988). A study of metamemory in amnesic and normal adults. Cortex, 24(1), 143-148.

Paris, S. G., \& Winograd, P. (1990). How metacognition can promote academic learning and instruction. Dimensions of thinking and cognitive instruction, 1, 15-51.

Peal, E., \& Lambert, W. E. (1962). The relation of bilingualism to intelligence. Psychological Monographs: general and applied, 76(27), 1-23.

Rahnev, D., Nee, D. E., Riddle, J., Larson, A. S., \& D’Esposito, M. (2016). Causal evidence for frontal cortex organization for perceptual decision making. Proceedings of the National Academy of Sciences, 113(21), 6059-6064.

Ransdell, S., Barbier, M. L., \& Niit, T. (2006). Metacognitions about language skill and working memory among monolingual and bilingual college students: When does multilingualism matter?. International Journal of Bilingual Education and Bilingualism, 9(6), 728-741. 
Reitan, R. M. (1958). Validity of the Trail Making Test as an indicator of organic brain damage. Perceptual and motor skills, 8(3), 271-276.

Roebers, C. M. (2017). Executive function and metacognition: Towards a unifying framework of cognitive self-regulation. Developmental Review, 45, 31-51.

Rubio-Fernández, P., \& Glucksberg, S. (2012). Reasoning about other people's beliefs: bilinguals have an advantage. Journal of Experimental Psychology: Learning, Memory, and Cognition, 38(1), 211.

Schnyer, D. M., Verfaellie, M., Alexander, M. P., LaFleche, G., Nicholls, L., \& Kaszniak, A. W. (2004). A role for right medial prefrontal cortex in accurate feeling-ofknowing judgments: Evidence from patients with lesions to frontal cortex. Neuropsychologia, 42(7), 957-966.

Schwartz, B. L., \& Díaz, F. (2014). Quantifying human metacognition for the neurosciences. In The cognitive neuroscience of metacognition (pp. 9-23). Springer Berlin Heidelberg.

Schwartz, B. L., \& Metcalfe, J. (2017, in press). Metamemory: An update of critical findings. Reference Module in Neuroscience and Biobehavioral Psychology. Elsevier Press.

Souchay, C., \& Isingrini, M. (2004). Age related differences in metacognitive control: Role of executive functioning. Brain and cognition, 56(1), 89-99.

Stocco, A., \& Prat, C. S. (2014). Bilingualism trains specific brain circuits involved in flexible rule selection and application. Brain and language, 137, 50-61.

Stocco, A., Yamasaki, B., Natalenko, R., \& Prat, C. S. (2014). Bilingual brain training: A neurobiological framework of how bilingual experience improves executive function. International Journal of Bilingualism, 18(1), 67-92.

Van Kleeck, A. (1982). The emergence of linguistic awareness: A cognitive framework. Merrill-Palmer Quarterly (1982-), 237-265. 
Wiecki, T. V., \& Frank, M. J. (2013). A computational model of inhibitory control in frontal cortex and basal ganglia. Psychological review, 120(2), 329.

Wiseheart, M., Viswanathan, M., \& Bialystok, E. (2016). Flexibility in task switching by monolinguals and bilinguals. Bilingualism: Language and Cognition, 19(1), 141-146.

Woolgar, A., Parr, A., Cusack, R., Thompson, R., Nimmo-Smith, I., Torralva, T., ... \& Duncan, J. (2010). Fluid intelligence loss linked to restricted regions of damage within frontal and parietal cortex. Proceedings of the National Academy of Sciences, 107(33), 14899-14902.

Yeung, N., \& Summerfield, C. (2014). Shared mechanisms for confidence judgements and error detection in human decision making. In The cognitive neuroscience of metacognition (pp. 147-167). Springer Berlin Heidelberg.

Zou, L., Ding, G., Abutalebi, J., Shu, H., \& Peng, D. (2012). Structural plasticity of the left caudate in bimodal bilinguals. Cortex, 48(9), 1197-1206. 


\section{Author biographies}

Peter Bright was educated at the Universities of Surrey (BSc,1991), Reading (MSc, 1993) and Cambridge (PhD, 1999). He has held research positions at the MRC Cognition and Brain Sciences Unit, Cambridge (1994-1995), King's College, London (1998-2001) and the University of Cambridge (2001-2005). He is currently Professor of Psychology and Director of the Brain and Cognition research group at Anglia Ruskin University, and is also a Principal Investigator in the Cambridge Neuroscience initiative at the University of Cambridge. His primary research interests are in memory, intelligence and executive function and he has published extensively in these fields.

Julia Ouzia is a teaching fellow at the Department of Psychology of Goldsmiths, University of London. Her research aims to evaluate bilingual cognition through a multidimensional approach, focussing on executive function, selective attention, metacognition, and probabilistic learning. In 2016, she co-authored the paper $A$ bilingual disadvantage in metacognitive processing (Folke, Ouzia et al., 2016) as well as the book chapter The bilingual advantage in the auditory domain (Ouzia \& Filippi, 2016).

Roberto Filippi is an Associate Professor in the Department of Psychology and Human Development at University College London, Institute of Education. He completed his studies at Birkbeck in London, mentored by Professor Annette Karmiloff-Smith and Professor Michael Thomas who have inspired his work in psycholinguistics and cognitive neuroscience adopting a Neuroconstructivist approach (D'Souza \& Filippi, 2017). His main research focus is on multi-language acquisition and its effects on cognitive development from infancy to older age. He is also the Director of the Multilanguage and Cognition Lab (MULTAC), part 
of the Centre for Language, Literacy \& Numeracy at UCL, Institute of Education. Some o his most recent publications include the metacognitive study described in this chapter (Folke, Ouzia, Bright, De Martino \& Filippi, 2016) and studies investigating the effects of multilanguage learning on control of interference and visuo-spatial memory in childhood and at later stages of life (Filippi, Leech, Thomas, Green \& Dick, 2012; Filippi, Morris, Richardson, Bright et al., 2015; Kerrigan, Thomas, Bright \& Filippi, 2016). 